\title{
CHRONIC SPINAL HEMISECTION IN RATS INDUCES A PROGRESSIVE DECLINE IN TRANSMISSION IN UNINJURED FIBERS TO MOTONEURONS
}

\author{
Victor L. Arvanian $1{ }^{,}{ }^{,}$, Lisa Schnell ${ }^{2}$, Li Lou ${ }^{1}$, Roozbeh Golshani ${ }^{3}$, Arsen Hunanyan $^{1}$, Arko \\ Ghosh $^{2}$, Damien D. Pearse ${ }^{3}$, John K. Robinson ${ }^{4}$, Martin E. Schwab ${ }^{2}$, James W. Fawcett ${ }^{5}$, \\ and Lorne M. Mendell ${ }^{1}$
}

1 Department of Neurobiology and Behavior SUNY at Stony Brook, Life Sciences Building, Stony Brook, NY 11794-5230 2 University of Zurich, Brain Research Institute, Winterthurerstr 190, $\mathrm{CH}-8057$ Zurich, Switzerland ${ }^{3}$ University of Miami Miller School of Medicine, Department of Neurological Surgery, Miami Project to Cure Paralysis, 1095 NW 14th Terrace, Miami, FL, 31364 Department of Psychology SUNY at Stony Brook, Stony Brook, NY $11794{ }^{5}$ Cambridge University Ctr Brain Repair, Robinson Way, Cambridge CB2 OPY, United Kingdom

\begin{abstract}
Although most spinal cord injuries are anatomically incomplete, only limited functional recovery has been observed in people and rats with partial lesions. To address why surviving fibers cannot mediate more complete recovery, we evaluated the physiological and anatomical status of spared fibers after unilateral hemisection (HX) of thoracic spinal cord in adult rats. We made intracellular and extracellular recordings at L5 (below HX) in response to electrical stimulation of contralateral white matter above (T6) and below (L1) HX. Responses from T6 displayed reduced amplitude, increased latency and elevated stimulus threshold in the fibers across from HX, beginning 1-2 weeks after HX. Ultrastructural analysis revealed demyelination of intact axons contralateral to the HX, with a time course similar to the conduction changes. Behavioral studies indicated partial recovery which arrested when conduction deficits began. In conclusion, this study is the first demonstration of the delayed decline of transmission through surviving axons to individual lumbar motoneurons during chronic stage of incomplete spinal cord injury in adult rats. These findings suggest a chronic pathological state in intact fibers and necessity for prompt treatment to minimize it.
\end{abstract}

\section{Keywords}

Hemisection; Spinal Cord Injury; Motoneuron; White matter; Ventrolateral funiculus; EPSP; Synaptic Transmission; Conduction Velocity; Demyelination

\footnotetext{
Correspondence should be addressed to: Dr. Victor L. Arvanian, Department of Neurobiology and Behavior, SUNY at Stony Brook, Life Sciences Building Room 550 Stony Brook, NY 11794-5230, Email: victor.arvanian@ sunysb.edu, Tel.: (631) 632-8653, Fax: (631) 632-6661.

*Present Address: Northport Veterans Affairs Medical Center 79 Middleville Road, Bld. 62, Northport, NY 11768

Publisher's Disclaimer: This is a PDF file of an unedited manuscript that has been accepted for publication. As a service to our customers we are providing this early version of the manuscript. The manuscript will undergo copyediting, typesetting, and review of the resulting proof before it is published in its final citable form. Please note that during the production process errors may be discovered which could affect the content, and all legal disclaimers that apply to the journal pertain.
} 


\section{Introduction}

Most spinal cord injuries (SCI; 90\%) are anatomically incomplete, with spared fibers spanning the damaged spinal segments. However, almost $50 \%$ of all spinal cord injuries are functionally complete, with total loss of sensation and muscle control below the level of the injury (Bunge et al., 1997; Burns et al., 1997; Little et al., 1999; Raineteau and Schwab, 2001). Therefore we hypothesize that some of the surviving fibers might not conduct or that their synaptic action is too weak to elicit functional effects.

As a model of incomplete injury we used lateral left spinal hemisection (HX), with the right side of the spinal cord remaining intact. This model allows comparison of how acute and chronic trauma affect the function of the surviving ventrolateral funiculus (VLF) fibers. The VLF contains ascending and descending fibers that are known to play an important role in a variety of sensory and motor functions, including somatosensory function, locomotion, bladder function and ejaculation (reviewed in Gramsbergen, 2001; Mayer and Esquenazi, 2003; Schallert and Woodlee, 2003; Shefchyk, 2006; Johnson, 2006; Jankowska and Edgley, 2006; Yukawa et al., 2008). Although a variable fraction of VLF fibers in the white matter tracts survive most SCI, it is not clear whether these surviving fibers can affect sensory relay nuclei above the injury or motoneurons below the injury, and whether transmission remains constant during the chronic phase after injury.

To study the time-related changes in transmission across the hemisection, we measured the intracellular synaptic response in lumbar segment 5 (L5) MNs on both the left (lesioned) or right (intact) sides, evoked by electrical stimulation of the ipsilateral or contralateral VLF at T6 (above the HX), and/or at L1 (below the HX). In the same cords, a tungsten electrode was placed into the right ventral horn to record evoked potentials extracellularly. These responses were compared in intact rats and at different time points after the HX, i.e., immediately, after 2 days, 1 week and up to 14 weeks. Prior to the terminal electrophysiological recordings, locomotor function of the rats was assessed in the Open Field, Irregular Horizontal Ladder and Narrowing Beam behavioral tests. After completion of electrophysiological recordings, the cords were processed to compare transmission across the HX with the anatomical measures, such as (i) severity of the injury (anatomical reconstruction), and (ii) the degree of myelination and numbers of axons on the uninjured side of the cord using light and electron microscopy.

Our studies reveal a decline in function of white matter across from the hemisection beginning about 1 week after injury. This was associated with demyelination of axons within that region and decreased locomotor function in challenging behavioral tasks. Some of these findings have been reported in abstract form (Arvanian et al., 2006; Lou et al., 2006; Golshani et al., 2008).

\section{Methods}

Spinal cord injury and all experimental procedures were performed in accordance with protocols approved by the Institutional Animal Care and Use Committee at SUNY- Stony Brook.

\section{Surgical procedure for the hemisection lesion}

Adult ( 210 g) female Sprague-Dawley rats were deeply anesthetized in 3\% isoflurane in 100\% $\mathrm{O}_{2}$ in an induction chamber $(1 \mathrm{~L})$. Anesthesia was maintained by administering $1.5 \%$ isoflurane in $100 \% \mathrm{O}_{2}$ through a face mask. Rectal temperature was maintained at $36^{\circ} \mathrm{C}$ via a heating pad and heart rate was monitored throughout the procedure. Dorsal laminectomy was performed to expose segments T9-T11 of the spinal cord using a superficial vein at T5-T6 as a landmark. The dura was slit $(1 \mathrm{~mm})$ at the midline at T10. A complete hemisection of the left hemicord at T10 was carried out with the tip of an iridectomy scissors, as follows: first, while holding 
the dura and lifting the spinal cord slightly, one tip of the scissors was passed through the entire thickness of the spinal cord dorsal to ventral at the midline; the left dorsal and ventral columns were then cut from lateral to the midline by closing other tip of scissors; finally, while keeping the cord elevated, one tip of the scissors was placed under the ventral surface of the spinal cord (up to the midline) and any uncut tissue in the left dorsal and ventral columns was cut ventral to dorsal up to the midline. After surgery, the muscles and skin were closed in layers with 4-0 suture. Antibiotic (Baytril, $5 \mathrm{mg} / \mathrm{kg}, 0.1 \mathrm{ml} \mathrm{sc}$ ), analgesic (Buprenorphine $5 \mathrm{mg} / \mathrm{kg}, 0.1 \mathrm{ml} \mathrm{sc}$ ), and $10 \mathrm{cc}$ of sterile saline were administered subcutaneously. Bladder function was not compromised by this surgery.

\section{Behavioral assessment (see Fig. 5)}

Observation of the freely moving animals in the Open Field (Basso et al., 1995) has revealed that rats and mice spontaneously recover weight-bearing stepping in the hind limb ipsilateral to lateral hemisection of the cervical or thoracic spinal cord (Webb and Muir, 2004; Ballermann and Fouad, 2006; Courtine et al., 2008). However, severe deficits with no recovery after unilateral hemisection of the cervical spinal cord were observed in more challenging tests, such as Narrowing Beam and Horizontal Rope (Ladder) tests, which measure primarily motor function (Shumsky et al., 2003; Liebscher et al., 2005). Therefore, in order to examine the locomotor function after lateral hemisection injury, the traditional Open Field BBB score was supplemented with the more challenging Irregular Horizontal Ladder and Narrowing Beam tests. Animals were pre-trained for 4 weeks before the surgery for these tests, which were carried out at weekly intervals for up to 6 weeks after surgery using the following protocols:

\section{BBB scoring}

Rats were allowed to move freely and scored during a 4 minute period for their ability to use their hindlimbs by two independent blinded observers. Joint movements, paw placement, weight support, and fore/hindlimb coordination were judged according to the 21-point BBB locomotion scale. Scores obtained by 2 independent observers were averaged for each hindlimb.

\section{Narrowing Beam Crossing}

Rats were trained to cross an elevated progressively narrowing beam (length $1.5 \mathrm{~m}$ ) starting from the wide end $(50 \mathrm{~mm})$ and terminating at the narrow end $(10 \mathrm{~mm})$. The beam was divided along its length into 30 equal units of $50 \mathrm{~mm}$ and the unit at which the first slip off the beam occurred was scored by 2 independent investigators. Trained non-injured rats completed the course with no slips or at most very few. Hemisection severely affected ability of rats to perform this challenging test due to a loss of balance and coordination. The first slip of either hindlimb was scored because slips occurred randomly and in most cases the slip of one hindlimb was followed by an immediate slip of the other hindlimb.

\section{Horizontal Irregular Ladder Crossing Test}

The animals were trained to run across a 1-meter-long horizontal ladder elevated from the ground. A $60 \mathrm{~cm}$ stretch was chosen for filming and analysis. To prevent habituation to a fixed bar distance, we placed the bars irregularly (1-4cm spacing). The number of foot slips or total misses in three trials was counted by two independent investigators and normalized by the total number of steps.

In addition to these tests, rats were observed in the Open Field at day 1 post-surgery (to evaluate the level of injury), and BBB scoring was carried at days 2 and 4 and then at weekly intervals for up to 6 weeks. Open field observations are particularly important after the initial days postHX when rats cannot perform the more challenging tests. 


\section{Criteria for the exclusion of animals}

Some animals were excluded from the study according to the following criteria: (i) rats showing weight-bearing stepping in the hind limb ipsilateral to the injury at day 1 post-HX indicating that the hemisection was not complete (1 rat of 105); (ii) animals not gaining weight, showing signs of autotomy, developing skin lesions or ruffled fur, squealing in response to gentle handling, licking a particular spot, or vocalizing were interpreted as suffering pain. These rats were sacrificed after evaluation by the attending veterinarian (15 rats of 105). The relatively large number of animals excluded for evidence of pain is consistent with the reported forelimb and hindlimb allodynia induced by hemisection injuries (Christensen et al., 1996; Hains et al., 2002).

\section{In vivo intracellular recordings from individual motoneurons (see Fig. 1) and extracellular recordings of the evoked potentials (see Figs. 2,3 ) in damaged spinal cord}

In the case of acute SCI, the electrophysiological recordings were made initially from the anesthetized (see Fig. 1) non-injured animal. After taking control measurements, the spinal cord was hemisected as above and recordings were made immediately after HX to demonstrate the effect of acute hemisection on the synaptic input to motoneurons from the contralateral white matter at the level of injury. In the case of chronic SCI, animals were allowed to survive for several days/weeks after the initial HX before recordings were made in a terminal procedure.

All rats studied electrophysiologically were deeply anesthetized using a ketamine $(80 \mathrm{mg} / \mathrm{kg}$, $0.5 \mathrm{ml}) / x y l a z i n e(10 \mathrm{mg} / \mathrm{kg}, 0.5 \mathrm{ml})$ mixture IP for induction, and $1 / 5$ dose after that, as needed. Heat rate and expired $\mathrm{CO}_{2}$ were monitored continuously. Dorsal laminectomy of the spinal cord was performed from T5 to T7 and from L1 to L6. A monopolar stimulating tungsten electrode was placed at T6 either on the side of the HX or contralaterally as described in text for VLF stimulation. This electrode entered the cord between the lateral side of the cord and dorsal root entry zone, between the T5-T6 dorsal roots. It was angled $25^{\circ}$ from the vertical in the sagittal plane (tip directed caudally), and lowered to a depth of $0.7 \mathrm{~mm}$. Stimulation was also carried out at L1 (see below).

Intracellular recordings from motoneurons (MNs) were made at $\mathrm{L} 5$ on either side of the cord using sharp glass microelectrodes (3M KAcetate; 50-70 M $\Omega$ resistance), coupled to an Axon Instruments amplifier, digitizer, and a PC. Motoneurons were identified by their antidromic response to stimulation of the cut L5 ventral root. The resting membrane potential of motoneurons used for analysis ranged from -45 to $-65 \mathrm{mV}$. For extracellular recordings, a tungsten electrode was used to record composite evoked potentials from the L5 ventral horn contralateral to the HX. It was positioned to enter the right side of the cord at the dorsal root entry zone, at an angle of $25^{\circ}$ from vertical in the sagittal plane (tip directed rostrally), and was lowered to a depth of $1.3 \mathrm{~mm}$. These recordings were amplified, digitized and stored on a PC. All records were analyzed off line using PClamp 9.0.

Synaptic responses on both sides of the cord were evoked by electrical stimulation VLF at T6 (rostral to the HX) both ipsilateral and contralateral to the HX. These recordings were made to detect the functional connections from axons passing through the injured region. If VLF stimulation above the injury level failed to evoke a response in L5 MNs, we moved the stimulating electrode caudal to the HX and recorded responses at L5 evoked by stimulation of VLF at L1. In many cases we managed to record responses evoked by stimulation of VLF rostral and caudal to HX in the same motoneuron. The VLF stimulus had a duration of $50 \mu \mathrm{s}$ and was delivered at $1 \mathrm{~Hz}$. The intensity was chosen to evoke a maximum response. It usually ranged from $40-70 \mu \mathrm{A}$ for the ipsilateral stimulus and $120-270 \mu \mathrm{A}$ for contralateral stimulus in uninjured cords, and 400-700 $\mu \mathrm{A}$ from contralateral T6 VLF in hemisected cords. The 
threshold and the maximum stimulation currents were determined by examining responses to currents of increasing intensity.

The amplitude of the maximum response was measured using an average of 200 (extracellular recordings) or 50 (intracellular recordings) consecutive responses. Responses to a given stimulus were averaged over all motoneurons recorded in each rat. These average values were compared over all animals in a given condition, i.e. the degrees of freedom are derived from the number of animals, not the total number of cells. Data were compared first by carrying out one-way ANOVA (Sigmastat 2.0). If significant differences were observed between the groups, a Student-Newman-Keuls test was used for pairwise multiple comparisons between them.

\section{Histology to determine extent of the injury}

After completion of electrophysiological recording the rats were intracardially perfused and spinal cords prepared for morphological evaluation of the injury site. A 1-cm segment of cord at the lesion zone was cut on a cryostat at $10 \mu \mathrm{m}$, and the Cresyl Violet stained sections were viewed using a Zeiss Axioskop upright microscope. Images were captured using a Spot RT camera and ImagePro Plus software (Media Cybernetics, Inc.) and used for reconstructions of the injury site, as previously described (Liebscher et al., 2005; Arvanian et al., 2006; see Fig. 1).

\section{Estimation of myelinated and total axon counts}

Plastic embedding of a 2-mm-long piece of the fixed spinal cord at the lesion epicenter was prepared as described previously (Pearse et al., 2005; Fouad et al., 2005). Total numbers of myelinated axons in the VLF region were counted using computer-assisted microscopy and Stereoinvestigator software (MicroBrightfield) in three $1 \mu \mathrm{m}$ plastic toluidine-blue stained semi-thin transverse sections taken from the tissue block. The three values were then averaged for a final estimate. For myelinated/unmyelinated axon ratios in the VLF, thin sections from the tissue block were examined and photographed using a Philips CM10 electron microscope. Total fiber number was calculated by multiplying myelinated axon count and ratio of unmyelinated to myelinated axons and adding the resulting number to the myelinated axon count.

Electron micrographs prepared for myelinated axon counts were also used for the calculation of the $\mathrm{G}$ ratio. The $\mathrm{G}$ ratio is defined as a ratio of myelin sheath thickness to the diameter of the axon (Keirstead et al, 2005). Measurements were performed on 8 micrographs from random fields of the VLF (16,500 magnification) with every myelinated axon within the image analyzed; 200-250 axon profiles were sampled per animal ( $\mathrm{n}=3$ per group). Non-symmetrical axon diameters were measured along two different axes to yield more accurate values. One way ANOVA analysis was performed followed by a Tukey multiple comparisons post-test to compare groups. A p value of $<0.05$ was deemed significant.

\section{Results \\ VLF to motoneuron connections in normal animals}

In uninjured rats, stimulation of the left VLF at T6 evoked responses in ipsilateral L5 motoneurons averaging $5.8 \pm 0.9 \mathrm{mV}(\mathrm{n}=14)$ in peak amplitude and $1.4 \pm 0.2 \mathrm{~ms}$ in latency (i.e. measured from stimulus artifact to response onset) (Fig. 1). Stimulation of the contralateral right VLF at T6 evoked a synaptic response in the same motoneurons, but these responses exhibited a somewhat smaller peak amplitude $(2.8 \pm 0.3 \mathrm{mV}, \mathrm{n}=14)$ and markedly longer latency $(6.0 \pm 0.7 \mathrm{~ms})$. The difference in latency of the response from contralateral and ipsilateral VLF was statistically significant $(\mathrm{p}<0.05, \mathrm{n}=14)$. In addition, the shape of these 
responses was very different. The short-latency responses from ipsilateral VLF exhibited a brief rise time and consecutive responses (at $1 \mathrm{~Hz}$ frequency) were almost identical during the rising phase (see insets in Fig 1ai). In contrast, the longer-latency responses from contralateral VLF had markedly longer rising time-to-peak and showed greater fluctuation rate in both amplitude and latency (see insets in Fig 1bi). The other difference was the significantly higher level of stimulus intensity required to evoke a maximal contralateral response, i.e., $55.2 \pm 13.5$ $\mu \mathrm{A}$ for the ipsilateral stimulus and $198.4 \pm 27.5 \mu \mathrm{A}$ for the contralateral stimulus, respectively $(\mathrm{p}<0.05, \mathrm{n}=14)$. The short latency and high reliability of the ipsilateral response suggests that it was almost certainly monosynaptic. The contralateral response is more difficult to characterize. It required much higher stimulus current suggesting the possibility that smaller, slower conducting fibers were responsible, and the long latency and fluctuations suggest that additional synapses were probably involved in this crossed projection.

\section{VLF to motoneuron connections after spinal cord hemisection}

After measurements of ipsilateral and contralateral responses in uninjured spinal cord, we performed a HX of the left lateral side of the cord at T10 while the animal was anesthetized, and the same responses were examined (Fig. 1-ii). As expected, the monosynaptic response in motoneurons at L5 from stimulating ipsilaterally (at T 6) above the lesion (T10) vanished. However, in the same motoneuron the long latency responses following stimulation of the contralateral right VLF at T6 above the HX remained, and the peak amplitude of these responses was not significantly different from that prior to $\mathrm{HX}$ (i.e., $2.8 \pm 0.7 \mathrm{mV}$ pre-HX vs $2.5 \pm 0.5 \mathrm{mV}$ post-HX, $\mathrm{n}=5, \mathrm{p}>0.05)$. These results suggest that the surgery did not produce immediate damage to the contralateral side.

To investigate the effects of chronic hemisection on these connections, hemisected rats were allowed to survive for up to 14 weeks, and electrophysiological recordings were carried out in terminal experiments at 2 days, 1 week, 2 weeks and 3- to - 14 weeks post-HX. The response in L5 motoneurons from contralateral T6 VLF stimulation was unaffected 2 days post-HX. However, beginning 1 week post-HX, this response declined and was markedly diminished by 2 weeks post-HX, even when high (up to $700 \mu \mathrm{A}$ ) intensity stimuli were applied (Fig. 1-iii). Furthermore, the responses remained diminished for the remainder of the 14 weeks period postHX that was investigated. While transmission from VLF rostral to the HX remained depressed, motoneurons still received inputs from the ipsilateral VLF caudal to HX, although these responses became somewhat smaller in amplitude in comparison to with non-injured ipsilateral controls (trace C-iii in Fig. 1). No change in latency was observed in these ipsilateral projections caudal to Hx. A summary of these results is presented in Fig. 1f. They suggest that there was a failure of conduction of the contralateral VLF through the segment of injury, which started to develop 1 week after the HX.

After completion of the electrophysiological recordings all rats were perfused, and crosssections were processed to evaluate the extent of the HX by digital reconstruction (Fig. 1e). We found that injuries were uniform, with complete lesion of the left half of the cord. There was no correlation between the size of the lesioned area and transmission from the contralateral VLF to ipsilateral motoneurons at the different times after HX (not shown).

\section{Conduction in the VLF contralateral to the lesion side: extracellular recordings}

The results in the previous paragraph suggested that there might be a delayed conduction deficit developing in unlesioned VLF axons contralateral to the injury. We tested this hypothesis first by recording extracellularly from VLF axons in response to stimulation above and below the lesion level (Fig. 2). In the uninjured spinal cord, electrical stimulation of the right VLF at T6 (ipsilateral to tungsten recording electrode) usually evoked a response that consisted of 2 or 3 peaks. Measurements of latency and frequency sensitivity suggested that the shortest-latency 
and high-frequency-resistant wave (i) represents the volley of action potentials in axons traveling through the white matter, while waves (ii) and (iii) represent synaptic responses (Fig. 2). These peaks were all preserved immediately after left $\mathrm{HX}$ with no significant changes in amplitude ( $>0.05, n=7$, Fig. 2). Further investigation revealed that all peaks were preserved even after transection of $2 / 3$ of the cord $(n=3$, Fig. 2), but were eliminated after complete transection ( $n=4$, Fig. 2).

In order to compare the ability of VLF to transmit through the intact side from segments above the hemisection to below, we measured the maximum amplitude of the volleys and synaptic response recorded in L5 in response to stimulation at T6 in intact (uninjured) preparations, after acute hemisection (Fig. 2), and after chronic hemisection (Fig. 3). In the same preparations we also recorded the stimulus intensity required to obtain a threshold response and the maximum response. We measured the amplitude of the extracellularly recorded evoked potentials as the peak to peak voltage of the volley and the synaptic response (volley of action potentials generally at $0.5-1 \mathrm{~ms}$, synaptic response generally at $3-5 \mathrm{~ms}$ ). The results are displayed in Table 1 where it is shown that there was no difference between the amplitude of the synaptic responses obtained after acute hemisection (compared to the intact). In contrast, after chronic hemisection, the synaptic responses were smaller and required greater stimulus intensity to obtain them. In addition, the action potential volleys conducted across the segment contralateral to HX were also substantially reduced after chronic hemisection (Table 1). The diminished responses from fibers crossing the injury segment on the contralateral side in chronically hemisected rats could not be enhanced by repositioning either the recording or stimulating electrode by as much as $0.5 \mathrm{~mm}$ rostrocaudal and/or mediolateral, indicating that the decline was not the result of the location of the electrodes, but rather was the result of diminished conduction across the HX. These results indicate that fibers passing through the region across from the HX underwent a change in their properties beginning about $1-2$ weeks after HX. In contrast, volleys measured from L1 stimulation (below HX) were similar to those obtained in intact animals.

\section{Intracellular recordings from motoneurons}

Consistent with these extracellular recording results, intracellular recordings from motoneurons contralateral and caudal to HX revealed marked changes in synaptic responses evoked by stimulation of VLF on the intact side of the spinal cord rostral to the level of the chronic HX (Fig. 3; Table 2- compare rows 1 and 2). The responses exhibited a decline in amplitude, an increase in latency and an increase in the stimulus intensity required to elicit the maximum response ( $\mathrm{p}<0.05$, One Way ANOVA). In these experiments we also systematically determined the same parameters in response to stimulation at L1, caudal to HX. As observed in Table 2 (see also Fig. 3) responses from L1 after chronic T10 HX were similar to those observed in the intact spinal cord. The difference in latency of synaptic responses evoked from above and below T10 permitted an estimate of conduction velocity of fibers crossing this segment. It averaged $39 \pm 5 \mathrm{~m} / \mathrm{s}(\mathrm{n}=7)$ in uninjured cords and $22 \pm 4 \mathrm{~m} / \mathrm{s}(\mathrm{n}=10)$ in chronically hemisected cords $(\mathrm{p}<0.05)$. These findings suggest that fibers passing directly across from the HX were affected by the HX but that a population of propriospinal fibers in lumbar cord was relatively unaffected in their properties despite T10 HX.

\section{Estimation of myelinated and total axon counts in the region of the VLF}

We used light and electron microscopy to investigate quantitatively whether the decay of transmission and the decrease in conduction velocity following chronic HX was due to a decrease in either total axon number or the number of myelinated axons within the white matter contralateral to the HX. After completion of electrophysiological recordings, animals were perfused and spinal cords prepared for morphological evaluation at different time points postinjury: 10 min post-HX (acute injury) and 2- or 6- weeks post-HX (chronic injury; 4 rats in 
each group). Tissue specimens were then evaluated for central axon myelination on the right side of the thoracic spinal cord at T10 (the intact side). A decreasing trend was observed in total axon number with the onset of chronic HX $(258,135 \pm 22,335$ acute HX; 194,487 $\pm 81,082$ two wks post-HX; $191,766 \pm 25,252$ six wks post-HX), but there was no statistically significant difference between the three groups (one way ANOVA, Kruskal-Wallis test, $\mathrm{p}>0.05$ ).

Importantly, we noted a statistically significant decrease in the number of myelinated axons in the spared white matter in chronic versus acute HX rats (i.e. 99,491 $\pm 3,222$ acute $\mathrm{HX}$ vs 56,480 \pm 7,094 two wks post-HX and 62,632 $\pm 2,809$ six wks post-HX, p<0.05) (Fig. 4). The percentage of myelinated fibers, calculated as a percent of the total number of axons, was lower in chronically vs acutely $\mathrm{HX}$ rats ( $38 \pm 3 \%$ acute $\mathrm{HX}, 28 \pm 2 \%$ two wks post-HX and $35 \pm 2 \%$ six wks post-HX), but these differences were not statistically significant ( $p>0.05)$.

Examination of the VLF revealed a mixed population of both large and small diameter axons with various degrees of myelin thickness of each animal, as expected for the different axonal populations within this tract (Antonio-Green et al, 2002). The $\mathrm{G}$ ratio for the uninjured controls was determined to be $43.86 \pm 3.26 \%$. Only after chronic SCI was there a significant change in the $\mathrm{G}$ ratio, a decrease to $36.25 \pm 3.76 \%$, $\mathrm{p}<0.001$. No difference was seen between acute SCI and uninjured groups. The decrease in $\mathrm{G}$ ratio demonstrates that the thickness of myelin wraps per axon was significantly less in animals in the chronic SCI phase.

\section{Behavioral assessments}

Prior to HX, rats were pretrained for 4 weeks and locomotor behavior was observed using the open field BBB analyses, the Irregular Horizontal Ladder Crossing test and the Narrowing Beam Crossing test. Scores were taken prior to HX and then at different time points post-HX (Fig. 5). Consistent with previous observations (Ballerman and Fouad, 2006;Courtine et al., 2008), spontaneous partial recovery of locomotion of both hindlimbs, ipsilateral and contralateral to $\mathrm{HX}$, occurred during the 2 weeks following lateral $\mathrm{HX}$ of the thoracic spinal cord (Fig. 5). In the case of the open field BBB analyses, when the rats were not challenged, the degree of locomotor recovery was high and most rats displayed weight-bearing plantar stepping of both hindlimbs, although rotation of the hindlimbs was characteristic for the majority of hemisected rats. In contrast, an obvious and severe impairment was revealed when the rats performed more challenging tasks, e.g. the Irregular Horizontal Ladder Crossing test and the Narrowing Beam Crossing tests which were more challenging (Fig. 5). In all three tests the locomotor recovery of both hindlimbs reached a plateau at about 2 weeks post-HX and further recovery did not take place. Interestingly, this time point coincided with the decline of transmission in the contralateral VLF across from the HX.

\section{Discussion}

The major finding from this research is that hemisection at $\mathrm{T} 10$ reduces transmission from the contralateral white matter above the hemisection to target cells in the lumbar spinal cord. The deficits in conduction for fibers running through the segment that had been hemisected contralaterally did not develop immediately after hemisection, but only after 1-2 weeks. It was measured as a marked decline in amplitude of the conducted volleys and synaptic responses below the segment of HX. In chronically hemisected rats these responses were always subthreshold for action potential generation, which required intracellular recording in order to be measured. The latency of these synaptic responses was increased suggesting a reduction of the conduction velocity of the axons (Figs. 1-3). The electrical threshold to obtain fiber volleys and synaptic responses was elevated by roughly a factor of 10 . All of these changes are suggestive of alterations in the properties or composition of the fiber tract spanning the segment opposite the HX. No such changes in electrical threshold and conduction velocity were observed in fibers activated below the hemisection (e.g., at L1) although a modest decline in 
the synaptic potentials in motoneurons was observed from surviving axons ipsilateral to the hemisection.

The responses evoked by VLF stimulation below the chronic hemisection (Fig. 1) were probably elicited largely by intact ascending and descending propriospinal fibers in the VLF (Jankowska et al., 2003;Reed et al., 2006;Reed et al., 2008) extending from L1 to L5 and synapsing with motoneurons (Petruska et al., 2007). Our studies provide little information concerning the mechanism by which this change in conduction occurs. Damage to the cord could result in inflammation (reviewed in Hagg and Oudega, 2006;Donnelly and Popovich, 2008), release of nitric oxide (reviewed in Kapoor et al., 1999), and other pathological changes resulting in eventual dysfunction of axons contralateral to the injury.

Previous in vivo studies using the contusion or compression models (Blight, 1983; Felts et al., 1997; Kapoor et al., 1999; Nashmi and Fehlings, 2001) have revealed similar declines in conduction although the time course is very different. In contrast to the present work where HX had an effect beginning only 1-2 weeks after the injury, contusion or compression produces a virtually immediate deficit in conduction which can display some recovery. These discrepancies probably reflect the differences in the injury which in the case of contusion or compression involves virtually the entire cord unlike HX where the initial damage is more limited (see also Siegenthaler et al. (2007) for comparison of transection and contusion injuties). The conduction studies described here indicate that deficits spread across the cord from the HX and to a limited extent to segments below. Such changes might also occur after contusion or compression, but would be obscured by the changes taking place immediately after injury.

The threshold and conduction velocity of the volleys recorded here indicates that only the largest myelinated fibers were being monitored in these experiments. We can say little about smaller fibers, which may not have been affected to the same extent. Indeed, clinical observations such as preservation of somatosensation associated with the Brown Sequard syndrome indicate that numerous fibers contralateral to a hemisection probably remain able to conduct through this region.

The mechanisms underlying the changes in conduction observed here are not clear at present. Our results suggest that fibers are present in VLF contralateral to the HX as observed by quantification of axonal profiles (Fig. 4). Some decline in the number of VLF axons as well as demyelination was observed in the contralateral white matter with a time course consistent with the electrophysiological changes measured here. The statistically significant difference observed between the average $\mathrm{G}$ ratios of chronically injured animals and uninjured controls (but not between acutely injured animals and controls) indicates that in chronic rats there was a significant reduction in the degree of myelination across all axons, and not just in the percentage of axons that are myelinated. This change could contribute to the observed loss of signal propagation at this time.

The reduction in myelin integrity may result from the death or dysfunction of the myelinating glia associated with these axons; oligodendrocytes have been shown to undergo apoptosis in regions far removed from the primary site of contusion injury from days to weeks post-injury (Shuman et al, 1997), a timeframe which would fit well with the changes reported here.

Following a loss of the original myelinating glial cell and demyelination, the axons may then be remyelinated by oligodendrocytes generated from endogenous precursors (Crang et al 2004), thus exhibiting thinner myelin sheaths. Oligodendrocyte cell death has been shown to result in a decline of myelin integrity and a consequential decline of signal propagation in other SCI models (Keirstead et al, 2005). An extensive literature demonstrates chronic demyelination of axons following spinal cord injury in humans and in rat models, and suggests that 
remyelination strategies may be a feasible approach for eliciting recovery of function (Shuman et al., 1997; McTigue et al., 2000; Blight, 2002; Guest et al., 2005; Black et al., 2006).

The reduction in the number of myelinated axons in this study (about 40\%) was not sufficiently great to account for the profound loss of the shortest latency electrophysiological responses which are due to volleys in myelinated fibers. This suggests that the surviving fibers had other deficits, e.g., in transmembrane ionic gradients or in Na channel function as has been suggested for the decline in conduction following compression injuries (Shi and Blight, 1996; Schwartz and Fehlings, 2001). This could lead to conduction blocks or a decline in conduction velocity which would desynchronize the action potential volleys making them more difficult to detect. The decreased synaptic response may have been due additionally to diminished synaptic transmission on target cells as has been observed for spinal synapses of afferent fibers that have been transected (Eccles et al., 1959; Mendell et al., 1995).

The 2-week time point, when the decline of transmission through the contralateral VLF had reached a maximum, marked the end of spontaneous locomotor recovery of hindlimb function (Fig. 5). Numerous additional studies have shown that spontaneous recovery of hindlimb function and locomotor recovery ends 2 weeks after lateral HX (Webb and Muir, 2004;Ballermann and Fouad, 2006;Park et al., 2007;Courtine et al., 2008). Anatomical and behavioral studies indicate that the degree of locomotor recovery following a lesion of the spinal cord is directly correlated with the number of fibers remaining in the ventrolateral spinal cord, thus pointing to the role of these fibers in motor function (You et al., 2003). Robust spontaneous locomotor recovery during the first two weeks post lateral $\mathrm{HX}$ has been attributed to recovery from the initial spinal shock and enhanced anatomical plasticity of propriospinal/ reticulospinal relay connections (Bareyre et al., 2004;Ballermann and Fouad, 2006;Courtine et al., 2008). However, it is not clear from these previous studies if the strengthened anatomical projections establish functional connections to lumbar motoneurons. The importance of these anatomical projections in determining the extent of recovery after $\mathrm{HX}$ adds significance to the present results. Here we show an association between the loss of functionality of the ipsilateral and contralateral projections in the largest fibers in the white matter through the segment of the HX and the sustained deficits in locomotor function of both hindlimbs while performing challenging behavioral tasks (Fig. 5).

In conclusion, this study is the first demonstration of the delayed decline of transmission through surviving descending axons to individual lumbar MNs induced by chronic incomplete spinal cord injury in adult rats. These findings may be useful experimentally since they provide a readily measured end point to evaluate strategies designed to minimize secondary effects of injuries.

Also, since clinical correlations in spinal cord-injured patients have demonstrated the validity of the rodent model for the study of neurological dysfunction after acute and chronic injuries (reviewed in Gramsbergen, 2001; Lou et al., 2006), our results suggest that in order to minimize and/or reverse developing conduction deficits, an appropriate treatment to minimize disruption of functional transmission by fibers surviving the injury should be introduced as soon as possible after the initial injury. However, the optimal timing for such treatment might be quite different in humans due to their larger size. This will require further evaluation.

\section{Acknowledgments}

We thank Ms. Lauren Callier, Mr. Alex Tolpygo, Ms. Maria Amella and Ms. Katherine Leisha (Stony Brook) for technical support. Dr. Thomas Zimmerman and his staff (Stony Brook) for extensive veterinarian support, Ms. Raisa Puzis and Ms. Margaret Bates of the electron microscopy core facility (Miami), and Mr. Amitbhai S. Patel (Miami) for his help with microscopy image analysis. This study was supported by grants from the Christopher Reeve Paralysis Foundation, NIH (NINDS) and the NY State Spinal Cord Injury Research Board. 


\section{References}

Antonino-Green DM, Cheng J, Magnuson DS. Neurons labeled from locomotor-related ventrolateral funiculus stimulus sites in the neonatal rat spinal cord. J Comp Neurol 2002;442:226-38. [PubMed: 11774338]

Arvanian VL, Bowers WJ, Anderson A, Horner PJ, Federoff HJ, Mendell LM. Combined delivery of neurotrophin-3 and NMDA receptors 2D subunit strengthens synaptic transmission in contused and staggered double hemisected spinal cord of neonatal rat. Exp Neurol 2006;197:347-52. [PubMed: 16289170]

Arvanian VL, Schnell L, Horner PJ, Bowers WJ, Federoff HJ, Schwab ME, Mendell LM. Combination Treatment With NT-3, NMDA-2d Subunits, And Anti-Nogo-A Antibody Increases Connections Of Transected Lateral Funiculus. Fibers To Lumbar Motoneurons Society For Neuroscience Abstracts \#555.2. 2006

Ballermann M, Fouad K. Spontaneous locomotor recovery in spinal cord injured rats is accompanied by anatomical plasticity of reticulospinal fibers. Eur J Neurosci 2006;23:1988-96. [PubMed: 16630047]

Bareyre FM, Kerschensteiner M, Raineteau O, Mettenleiter TC, Weinmann O, Schwab ME. The injured spinal cord spontaneously forms a new intraspinal circuit in adult rats. Nat Neurosci 2004;7:269-77. [PubMed: 14966523]

Basso DM, Beattie MS, Bresnahan JC. A sensitive and reliable locomotor rating scale for open filed testing in rats. Journal of Neurotrauma 1995;12:1-21. [PubMed: 7783230]

Black JA, Waxman SG, Smith KJ. Remyelination of dorsal column axons by endogenous Schwann cells restores the normal pattern of Nav1.6 and Kv1.2 at nodes of Ranvier. Brain 2006;129:1319-29. [PubMed: 16537565]

Blight AR. Axonal physiology of chronic spinal cord injury in the cat: intracellular recording in vitro. Neuroscience 1983;10:1471-86. [PubMed: 6664497]

Blight AR. Miracles and molecules--progress in spinal cord repair. Nat Neurosci 2002;(5 Suppl):105154. [PubMed: 12403984]

Bunge RP, Puckett WR, Hiester ED. Observations on the pathology of several types of human spinal cord injury, with emphasis on the astrocyte response to penetrating injuries. Adv Neurol 1997;72:305-15. [PubMed: 8993707]

Burns SP, Golding DG, Rolle WA Jr, Graziani V, Ditunno JF Jr. Recovery of ambulation in motorincomplete tetraplegia. Arch Phys Med Rehabil 1997;78:1169-72. [PubMed: 9365343]

Christensen MD, Everhart AW, Pickelman JT, Hulsebosch CE. Mechanical and thermal allodynia in chronic central pain following spinal cord injury. Pain 1996;68:97-107. [PubMed: 9252004]

Courtine G, Song B, Roy RR, Zhong H, Herrmann JE, Ao Y, Qi J, Edgerton VR, Sofroniew MV. Recovery of supraspinal control of stepping via indirect propriospinal relay connections after spinal cord injury. Nat Med 2008;14:69-74. [PubMed: 18157143]

Crang AJ, Gilson JM, Li WW, Blakemore WF. The remyelinating potential and in vitro differentiation of MOG-expressing oligodendrocyte precursors isolated from the adult rat CNS. Eur J Neurosci 2004;20:1445-60. [PubMed: 15355312]

Donnelly DJ, Popovich PG. Inflammation and its role in neuroprotection, axonal regeneration and functional recovery after spinal cord injury. Exp Neurol 2008;209:378-88. [PubMed: 17662717]

Eccles JC, Krnjevic K, Miledi R. Delayed effects of peripheral severance of afferent nerve fibres on the efficacy of their central synapses. J Physiol 1959;145:204-20. [PubMed: 13621430]

Felts PA, Baker TA, Smith KJ. Conduction in segmentally demyelinated mammalian central axons. J Neurosci 1997;17:7267-77. [PubMed: 9295373]

Fouad K, et al. Combining Schwann cell bridges and olfactory-ensheathing glia grafts with chondroitinase promotes locomotor recovery after complete transection of the spinal cord. J Neurosci 2005;25:116978. [PubMed: 15689553]

Golshani R, Pearse DD, Lou L, Mendell LM, Arvanian VL. Decline of transmission to motoneurons from surviving fibers induced by chronic spinal cord hemisection in adult rats. Society for Neuroscience Abstract 2008:\#617.4.

Gramsbergen A. Normal and abnormal development of motor behavior: lessons from experiments in rats. Neural Plast 2001;8:17-29. [PubMed: 11530886] 
Guest JD, Hiester ED, Bunge RP. Demyelination and Schwann cell responses adjacent to injury epicenter cavities following chronic human spinal cord injury. Exp Neurol 2005;192:384-93. [PubMed: 15755556]

Hains BC, Everhart AW, Fullwood SD, Hulsebosch CE. Changes in serotonin, serotonin transporter expression and serotonin denervation supersensitivity: involvement in chronic central pain after spinal hemisection in the rat. Exp Neurol 2002;175:347-62. [PubMed: 12061865]

Hagg T, Oudega M. Degenerative and spontaneous regenerative processes after spinal cord injury. J Neurotrauma 2006;23:264-80. [PubMed: 16629615]

Jankowska E, Edgley SA. How can corticospinal tract neurons contribute to ipsilateral movements? A question with implications for recovery of motor functions. Neuroscientist 2006;12:67-79. [PubMed: 16394194]

Jankowska E, Hammar I, Slawinska U, Maleszak K, Edgley SA. Neuronal basis of crossed actions from the reticular formation on feline hindlimb motoneurons. J Neurosci 2003;23:1867-78. [PubMed: 12629191]

Johnson RD. Descending pathways modulating the spinal circuitry for ejaculation: effects of chronic spinal cord injury. Prog Brain Res 2006;152:415-26. [PubMed: 16198717]

Kapoor R, Davies M, Smith KJ. Temporary axonal conduction block and axonal loss in inflammatory neurological disease. A potential role for nitric oxide? Ann NY Acad Sci 1999;893:304-08. [PubMed: 10672255]

Keirstead HS, Nistor G, Bernal G, Totoiu M, Cloutier F, Sharp K, Steward O. Human embryonic stem cell-derived oligodendrocyte progenitor cell transplants remyelinate and restore locomotion after spinal cord injury. J Neurosci 2005;25:4694-705. [PubMed: 15888645]

Liebscher T, Schnell L, Schnell D, Scholl J, Schneider R, Gullo M, Fouad K, Mir A, Rausch M, Kindler D, Hamers FP, Schwab ME. Nogo-A antibody improves regeneration and locomotion of spinal cordinjured rats. Ann Neurol 2005;58:706-19. [PubMed: 16173073]

Little JW, Ditunno JF Jr, Stiens SA, Harris RM. Incomplete spinal cord injury: neuronal mechanisms of motor recovery and hyperreflexia. Arch Phys Med Rehabil 1999;80:587-99. [PubMed: 10326926]

Lou L, Garcia-Alias G, Mendell LM, Fawcett JW, Arvanian VL. Transmission through white matter contralateral to thoracic hemisection declines beginning several days after injury in parallel with enhanced expression of CSPGs in the vicinity of the lesion. Society for Neuroscience Abstracts 2007:\#801.1.

Mayer NH, Esquenazi A. Muscle overactivity and movement dysfunction in the upper motoneuron syndrome. Phys Med Rehabil Clin N Am 2003;14:855-83. [PubMed: 14580042]

McTigue DM, Popovich PG, Jakeman LB, Stokes BT. Strategies for spinal cord injury repair. Prog Brain Res 2000;128:3-8. [PubMed: 11105664]

Mendell LM, Taylor JS, Johnson RD, Munson JB. Rescue of motoneuron and muscle afferent function in cats by regeneration into skin. II Ia-motoneuron synapse. J Neurophysiol 1995;73:662-73. [PubMed: 7760125]

Nashmi R, Fehlings MG. Changes in axonal physiology and morphology after chronic compressive injury of the rat thoracic spinal cord. Neuroscience 2001;104:235-51. [PubMed: 11311546]

Park JP, Kim KJ, Phi JH, Park CK, Kim JH, Kang HJ, Lee D, Han KH, Wang KC, Paek SH. Simple measurement of spinal cord evoked potential: a valuable data source in the rat spinal cord injury model. J Clin Neurosci 2007;14:1099-105. [PubMed: 17719789]

Paxinos G, Watson C, Pennisi M, Topple A. Bregma, lambda and the interaural midpoint in stereotaxic surgery with rats of different sex, strain and weight. J Neurosci Methods 1985;13:139-43. [PubMed: 3889509]

Pearse DD, et al. Histopathological and behavioral characterization of a novel cervical spinal cord displacement contusion injury in the rat. J Neurotrauma 2005;22:680-702. [PubMed: 15941377]

Petruska JC, Ichiyama RM, Jindrich DL, Crown ED, Tansey KE, Roy RR, Edgerton VR, Mendell LM. Changes in motoneuron properties and synaptic inputs related to step training after spinal cord transection in rats. J Neurosci 2007;27:4460-71. [PubMed: 17442831]

Raineteau O, Schwab ME. Plasticity of motor systems after incomplete spinal cord injury. Nat Rev Neurosci 2001;2:263-73. [PubMed: 11283749] 
Reed WR, Shum-Siu A, Magnuson DS. Reticulospinal pathways in the ventrolateral funiculus with terminations in the cervical and lumbar enlargements of the adult rat spinal cord. Neuroscience 2008;151:505-17. [PubMed: 18065156]

Reed WR, Shum-Siu A, Onifer SM, Magnuson DS. Inter-enlargement pathways in the ventrolateral funiculus of the adult rat spinal cord. Neuroscience 2006;142:1195-207. [PubMed: 16938403]

Schallert T, Woodlee MT. Brain-dependent movements and cerebral-spinal connections: key targets of cellular and behavioral enrichment in CNS injury models. J Rehabil Res Dev 2003;40:9-17. [PubMed: 15077644]

Schwartz G, Fehlings MG. Evaluation of the neuroprotective effects of sodium channel blockers after spinal cord injury: improved behavioral and neuroanatomical recovery with riluzole. J Neurosurg 2001;94:245-56. [PubMed: 11302627]

Shefchyk SJ. Spinal mechanisms contributing to urethral striated sphincter control during continence and micturition: "how good things might go bad". Prog Brain Res 2006;152:85-95. [PubMed: 16198695]

Shi R, Blight AR. Compression injury of mammalian spinal cord in vitro and the dynamics of action potential conduction failure. J Neurophysiol 1996;76:1572-80. [PubMed: 8890277]

Shuman SL, Bresnahan JC, Beattie MS. Apoptosis of microglia and oligodendrocytes after spinal cord contusion in rats. J Neurosci Res 1997;50:798-808. [PubMed: 9418967]

Shumsky JS, Tobias CA, Tumolo M, Long WD, Giszter SF, Murray M. Delayed transplantation of fibroblasts genetically modified to secrete BDNF and NT-3 into a spinal cord injury site is associated with limited recovery of function. Exp Neurol 2003;184:114-30. [PubMed: 14637085]

Siegenthaler MM, Tu MK, Keirstead HS. The extent of myelin pathology differs following contusion and transection spinal cord injury. J Neurotrauma 2007;24:1631-46. [PubMed: 17970626]

Webb AA, Muir GD. Course of motor recovery following ventrolateral spinal cord injury in the rat. Behav Brain Res 2004;155:55-65. [PubMed: 15325779]

You SW, Chen BY, Liu HL, Lang B, Xia JL, Jiao XY, Ju G. Spontaneous recovery of locomotion induced by remaining fibers after spinal cord transection in adult rats. Restor Neurol Neurosci 2003;21:39_ 45. [PubMed: 12808201]

Yukawa Y, Kato F, Ito K, Horie Y, Hida T, Machino M, Ito ZY, Matsuyama Y. Postoperative changes in spinal cord signal intensity in patients with cervical compression myelopathy: comparison between preoperative and postoperative magnetic resonance images. J Neurosurg Spine 2008;8:524-8.

[PubMed: 18518672]

Exp Neurol. Author manuscript; available in PMC 2010 July 1. 

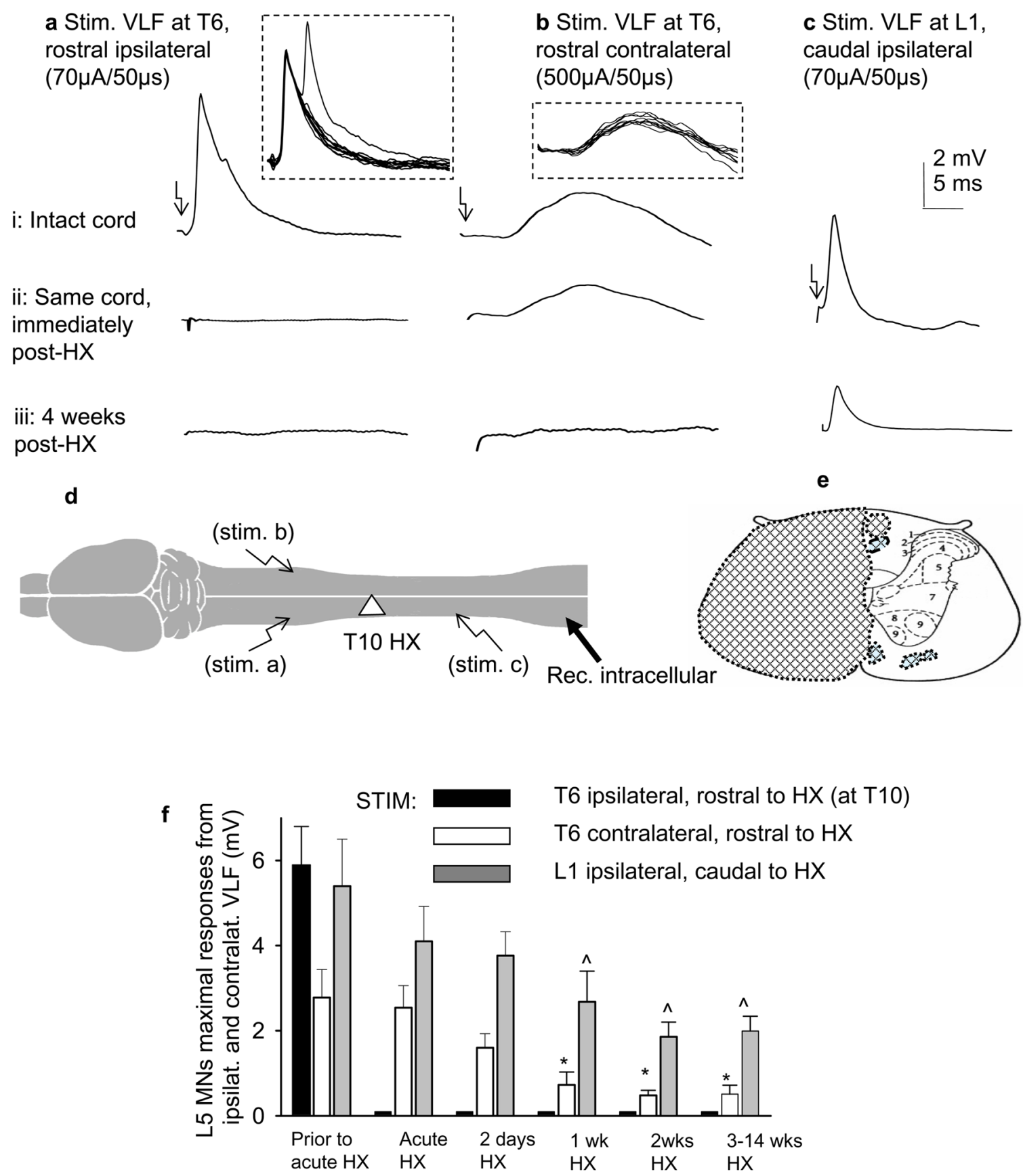

Fig. 1.

Chronic injury, but not acute injury, induces decay of transmission to motoneurons through white matter contralateral to HX. Intracellular recordings were made in vivo from L5 motoneurons ipsilateral to T6 hemisection. Stimulation of ipsilateral and contralateral VLF at T6 above the level of injury. a-c: Responses from (a) ipsilateral and (b) contralateral VLF rostral to HX, and (c) ipsilateral VLF caudal to HX. Records displayed are among the largest responses for each group (average of 50 consecutive traces), with the arrow indicating the stimulus artifact at the left. Insets: superimposed 10 responses from same cell evoked by stimulation of the ipsilateral and contralateral VLF, respectively. Conditions: (i) intact spinal cord, (ii) same cord as above, but 10 minutes after HX, (iii) different cord, 4 wks post-HX. d: 
Position of the recording and stimulating electrodes. e: Reconstruction of the injury from T10 cross-sections from the cord presented in (iii); reconstruction from 3 sections $50 \mu \mathrm{M}$ apart superimposed onto templates modified from (Paxinos et al., 1985). f: Summary of results demonstrating the decline in magnitude of motoneuron responses in L5 ipsilateral to $\mathrm{HX}$ at T10 (stimuli were delivered at T6 ipsilateral and contralateral to the HX, and at L1 ipsilateral to the HX; the symbols above some of the bars represent a significant decline from controls $(\mathrm{p}<0.05)$; all means were derived from $\mathrm{n}=5-9$ rats, and for each rat the response was an average of the maximum responses recorded intracellularly from 5 to 7 motoneurons). 


\section{a: Control (intact cord)}

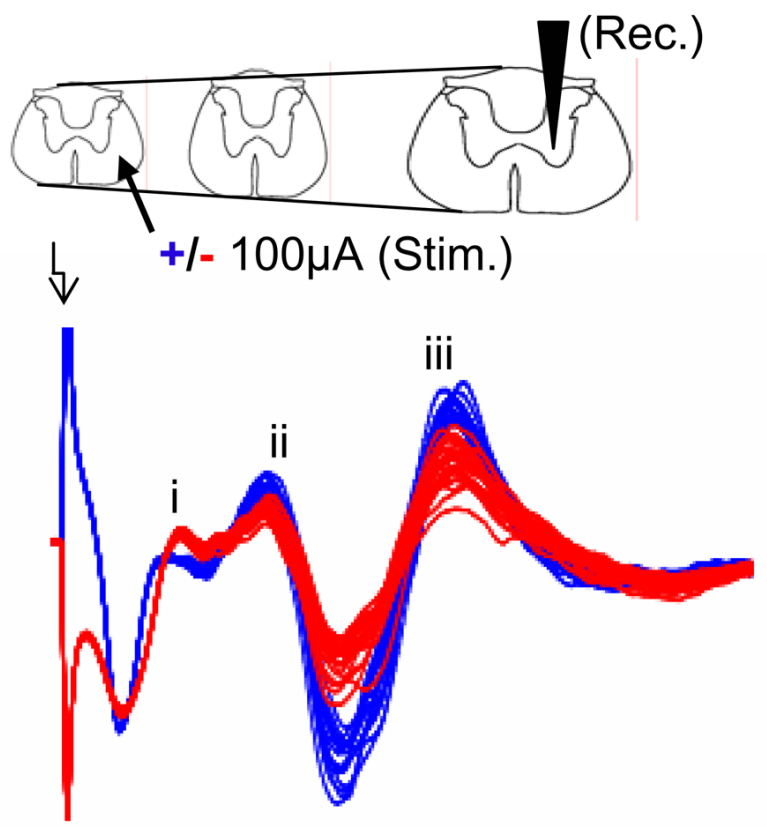

c: Overhemisection
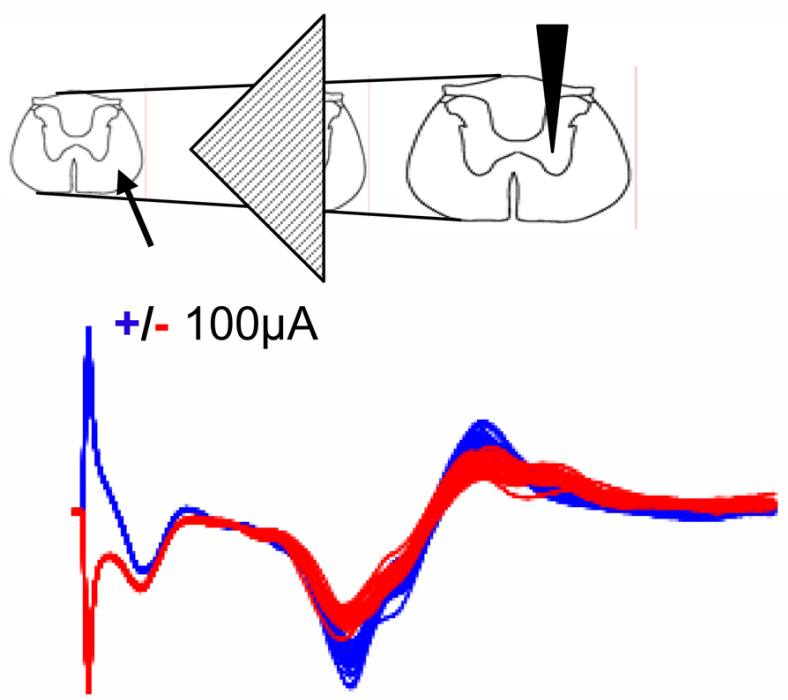

\section{b: 5 min post-Hemisection (at T10)}
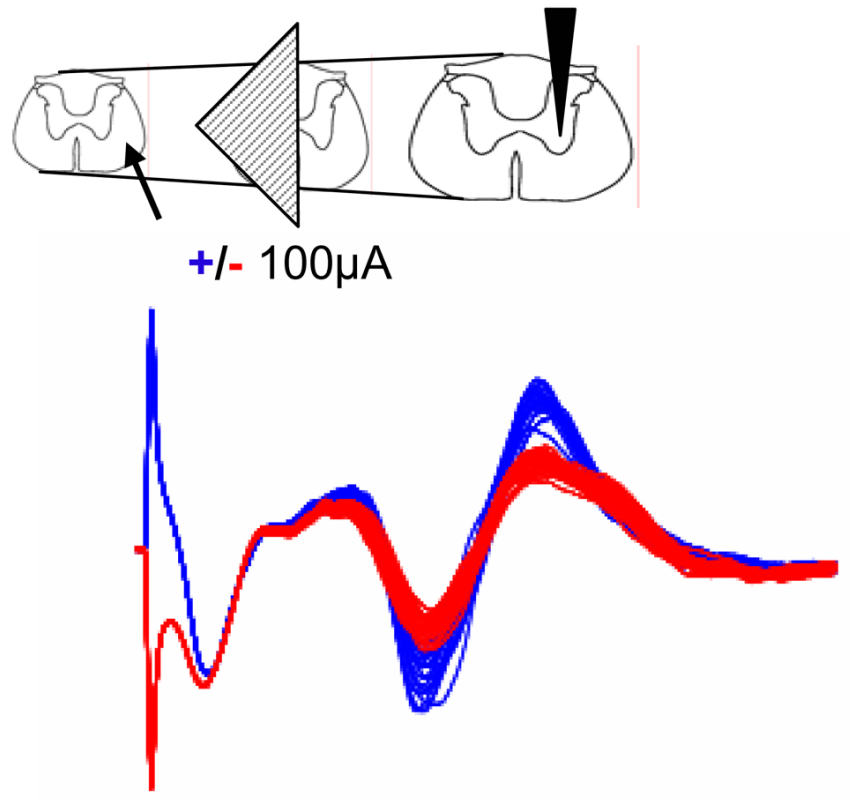

d: Complete transection
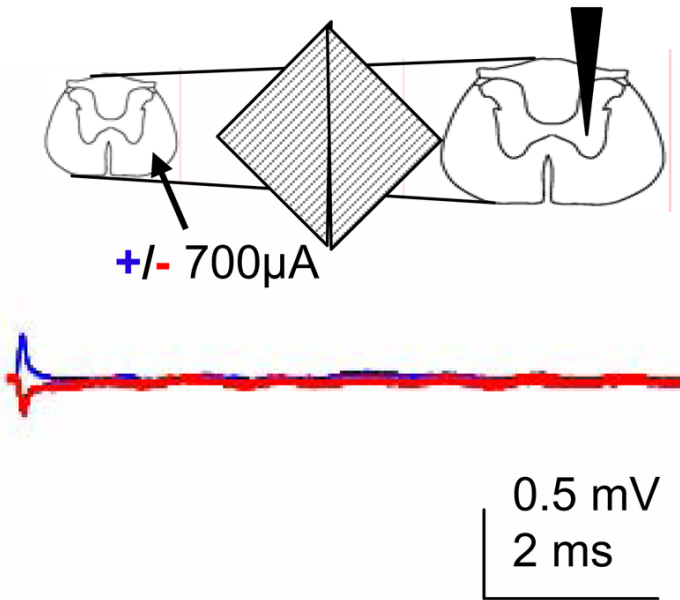

Fig. 2.

Extracellular responses in L5 ventral horn contralateral to HX elicited by stimulation at T6 contralateral to HX. Diagrams show positions of the recording tungsten electrode (right-side ventral horn) and the stimulating electrode (right side VLF), stimulus intensities (at $1 \mathrm{~Hz}$ stimulation rate) and the lesion at T10. All superimposed traces are the successive responses evoked by stimuli of opposite polarity (50 consecutive traces each polarity, blue and red) We confirmed the neural basis of the recorded waves by demonstrating their invariance in response to changing stimulus polarity. a: Representative traces recorded in the intact cord. Note a marked fluctuation in both amplitude and latency in up-going waves (ii) and (iii), but not in the shortest-latency up-going wave (i), at a stimulus frequency of $1 \mathrm{~Hz}$ (these fluctuations of waves ii and iii were even more apparent when the stimulation frequency was raised to $10 \mathrm{~Hz}$; 
not shown). b: Left hemisection (denoted as shaded triangle) did not induce marked changes of the evoked potentials conducted through the right uninjured side across from HX. c:

Hemisection of left cord extended to include half the right cord (overhemisection) resulted in smaller amplitude responses. d: Complete transection of the cord (both left and right sides) completely abolished evoked responses, even at higher stimulus intensity. 


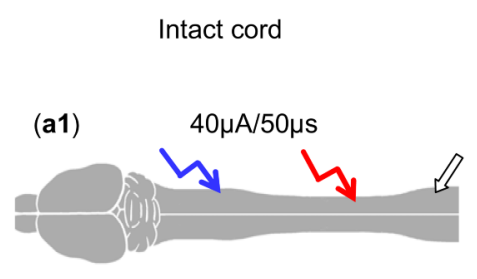

Chronic HX
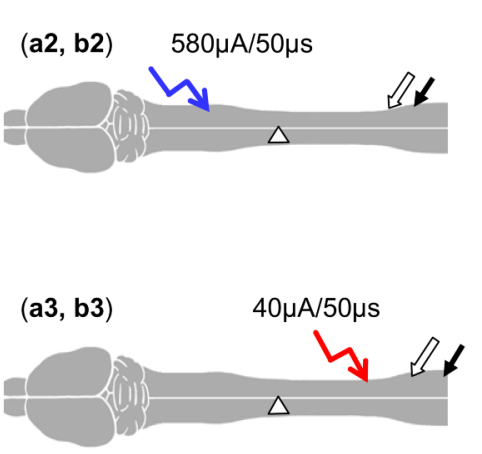

$\downarrow$

a: Intracellular recordings

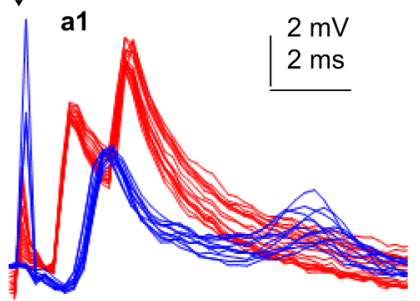

a2

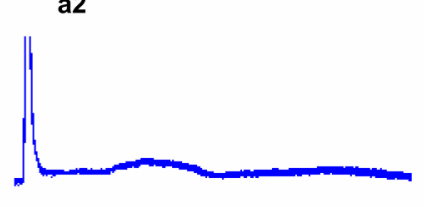

a3

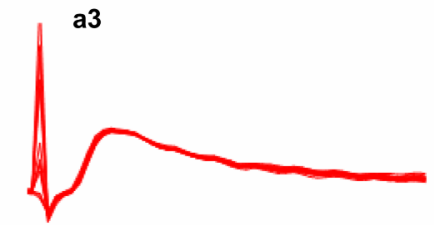

b: Extracellular recordings
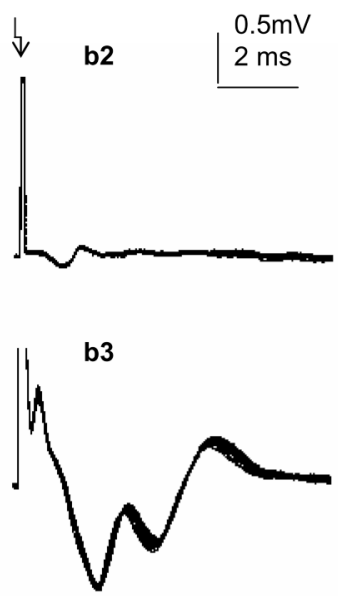

Fig. 3.

Intracellular and extracellular recordings demonstrating conduction deficit and decay of transmission contralateral to chronic HX. Diagrams show position of recording electrodes (intracellular - clear arrow and extracellular - solid arrow) and stimulating electrodes (red and blue), and stimulus intensity required to evoke responses in uninjured and chronically injured spinal cords. a1: intact spinal cord. Stimulation of right VLF at T6 elicits EPSP in an L5 motoneuron on the same side that is similar in amplitude and of longer latency than the response elicited in the same motoneuron by stimulation at L1. Intracellular records showing the difference in EPSP latency were used for measurements of conduction velocity rather than extracellular records because the latter were often contaminated by the stimulus artifact particularly from the caudal position (L1). a2, b2: chronic left hemisected spinal cord (two weeks post-hemisection). Intracellular and extracellular responses at right L5 ventral horn elicited by stimulation of right VLF at T6 (a2, b2) are considerably smaller than the responses elicited at the same electrodes by stimulation at L1 (a3, b3). 
T10, non-injured

a

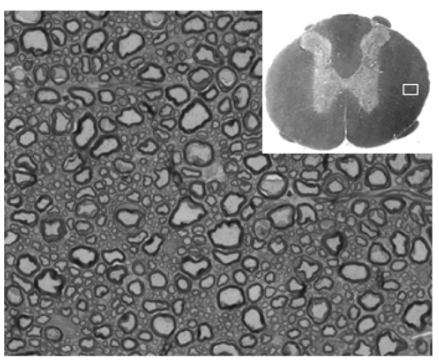

b

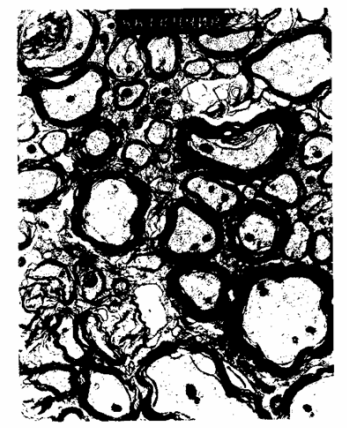

T10, 6 wks post-HX
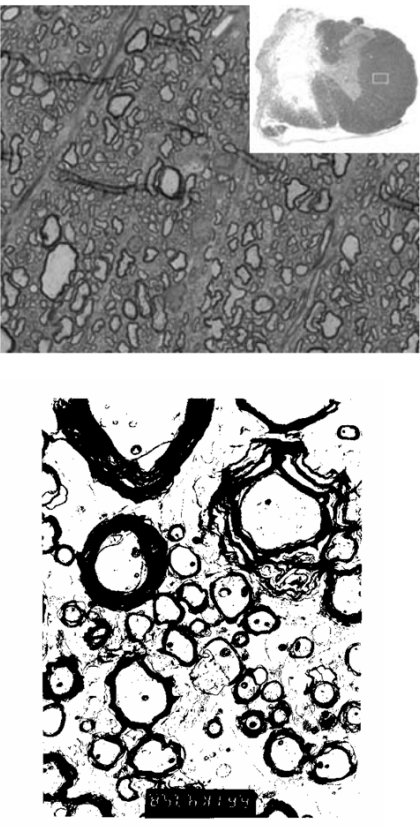

C

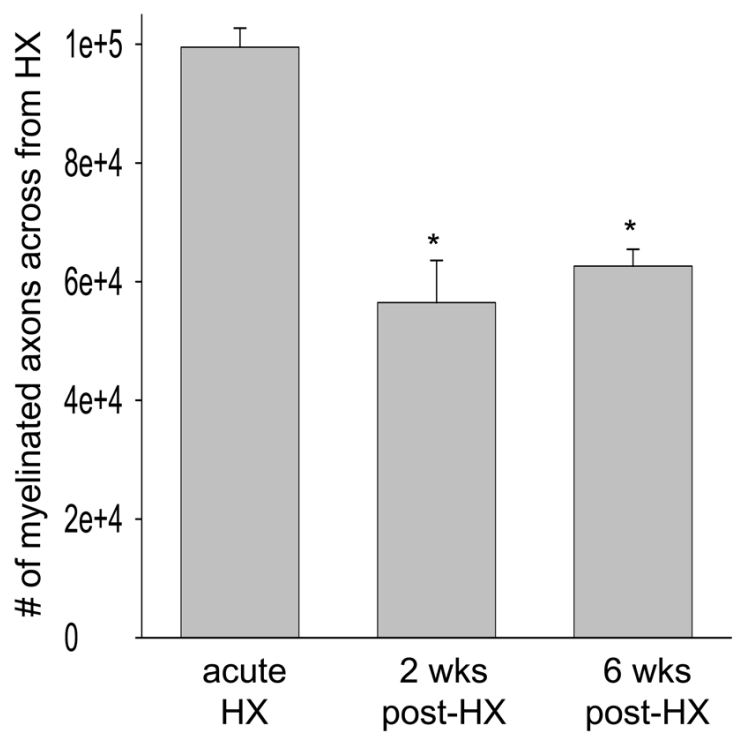

Fig. 4.

Analysis of the total and myelinated axon number in the spared white matter on the intact side. A and B: Representative 60x (a) and Electron Microscope (b) images of the white matter (from labeled area in the insets). C: Number of myelinated axons in the spared white matter across from HX. Note marked decrease in the number of central myelinated axons in the spared white matter on the intact side in chronic ( 2 weeks and 6 weeks post-HX) vs acute HX rats $(\mathrm{p}<0.05$, one way non-parametric ANOVA). 

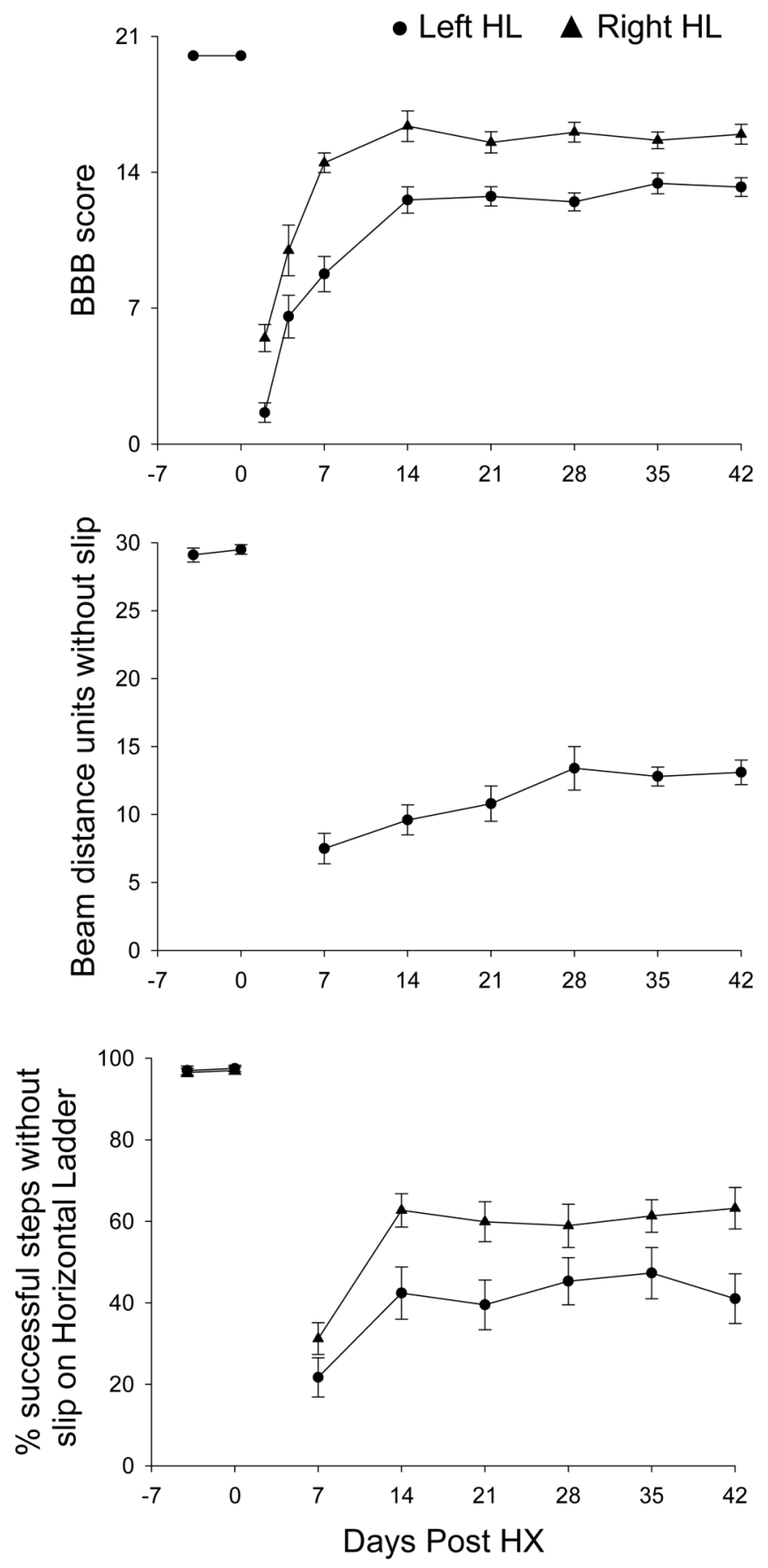

Fig. 5.

Spontaneous recovery of locomotor function of both ipsilateral and contralateral to HX hindlimbs plateaus at about 2 weeks post-HX. In addition to BBB open-field locomotion score, more challenging tests, Narrowing Beam and Horizontal Irregular Ladder, were used to assess hindlimb function ipsilateral and contralateral to the lesion. Data plotted as means \pm SEM with $\mathrm{p}<0.05$ for all values at post-HX time points vs pre-operation values. BBB-scoring during $1^{\text {st }}$ week post-HX revealed that all rats start with a very similar handicap (lesion severity). Note that function recovers spontaneously up to day 14 in all three tests, and after that the recovery plateaus. 


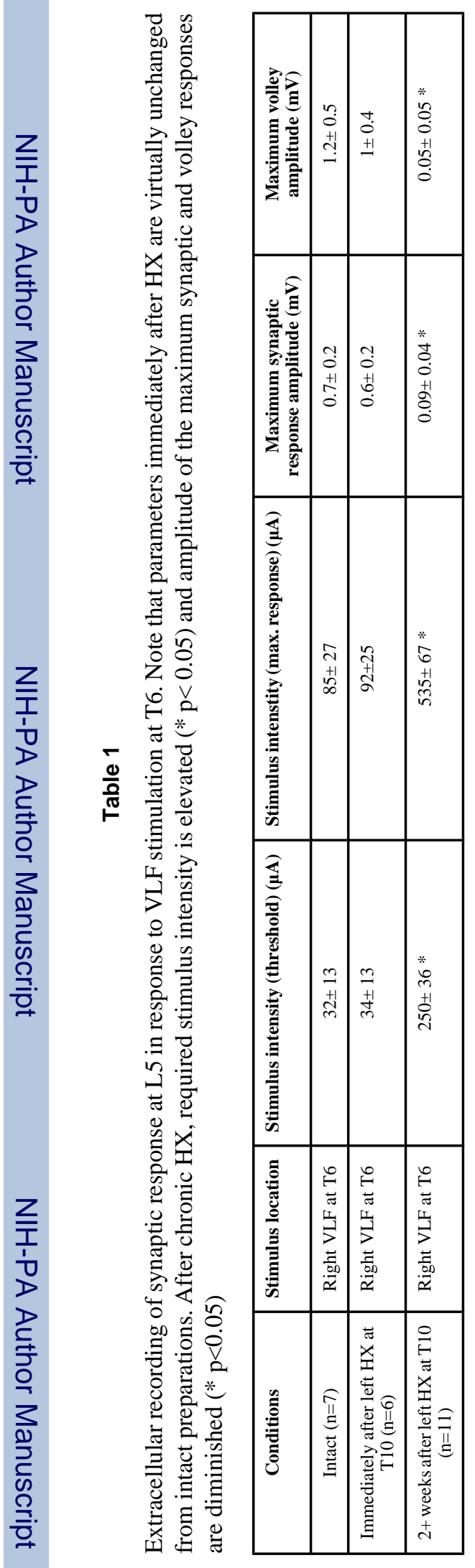

Exp Neurol. Author manuscript; available in PMC 2010 July 1. 


\section{Table 2}

Intracellular recording from motoneurons at L5 (right side of spinal cord) in response to stimulation of VLF at T6 and L1. Intact and chronic HX of left cord at T10. Note the difference between the responses elicited above the level of HX in intact and chronic HX cords (reduced response amplitude, increased latency, increased stimulus current required; $* \mathrm{p}<0.05)$. Note the similarity in the parameters in intact and injured cord when stimulation was at VLF below the HX

\begin{tabular}{|l|l|l|l|l|}
\hline Preparation & Stimulus location & Stimulus intensity (max. response) $(\boldsymbol{\mu A})$ & $\begin{array}{l}\text { Maximum response } \\
\text { amplitude }(\mathbf{m V})\end{array}$ & Latency (ms) \\
\hline Intact $(\mathrm{n}=5)$ & Right VLF (T6) & $76 \pm 15$ & $5.1 \pm 0.8$ & $1.3 \pm 0.2$ \\
\hline Chronic HX at T10 (n=7) & Right VLF (T6) & $514 \pm 54 *$ & $0.9 \pm 0.2 *$ & $1.8 \pm 0.2 *$ \\
\hline Intact (n=5) & Right VLF (L1) & $59 \pm 9$ & $4.5 \pm 0.7$ & $0.8 \pm 0.1$ \\
\hline Chronic HX at T10 (n=7) & Right VLF (L1) & $65 \pm 7$ & $2.5 \pm 0.6$ & $0.9 \pm 0.6$ \\
\hline
\end{tabular}

